\title{
Anti-style and the Postmodernist Novel
}

\author{
Brian Crews \\ Universidad de Sevilla
}

\begin{abstract}
A consideration of attitudes towards style in contemporary narratives leads to the conclusion that decorum and convention are often deliberately marked in order to draw attention to their artificiality. In particular, in what are sometimes called postmodernist novels, a critical stance is often adopted towards adequate or appropriate styles, so that anti-style, or a deliberate break with decorum or uniformity, highlights the fictitious nature of what is narrated. In the novels of B.S. Johnson, a combination of styles and deviations from them show that there is no such thing as an authoritative narrative, not even the author's, and, while the conventional nature of language, style and narrative is foregrounded, it is implied that there is always some alternative to the inevitable fabrications and distortions that they involve.
\end{abstract}

It might be said that style is something which some have and others do not. However, we know that style is a property of all texts, although, in some contemporary narratives, that style might well be called anti-style. Although Baroque existed in the seventeenth century, nowadays, anti-style can be associated with the French nouveau roman and has been steadily on the increase in many of what are often called postmodernist novels. Its effects and consequences are several, but, in particular, it has become a device which brings about defamiliarisation and draws attention to the conventional nature of style and narrative. However, before going on to look at examples, in this case from some of the postmodernist novels of B.S. Johnson, it should be made clear just what is meant by, not only anti-style, but style itself. 
Broadly speaking, we can speak of style as the shared language habits of a particular group or society at a given time, the linguistic habits or idiosyncrasies of one person, that which is characteristic of good, beautiful or effective writing, or the most effective way of saying something (Crystal and Davy 9-10). Of course there are linguistic conventions which belong to different kinds of discourse: these might be called the rules or conventions of rhetoric; but on the other hand, we often find idiosyncratic linguistic features within a conventional variety, which bring about specific effects, and for many, that is style. In fact, there is a tendency to focus on idiosyncratic features and the unexpected as being more noticeable and, therefore, significant in descriptions of style. However, Seymour Chatman cuts across all of this and defines the following categories: a normative type which is characteristic of good writing; an individual type which is idiosyncratic and objectively distinct; style as an ornamental addition to content; and style as a verbal reflection of decorum, that is, the most appropriate manner for a particular social context (399-422).

Style as a normative type and as a verbal reflection of decorum essentially belong to the public domain, whereas style as an individual type and ornament are more clearly personal and private questions. In fact, the question of style has sometimes been seen in terms of a public or private game where the public game involves the practice of rhetorical conventions; that is, the linguistic and cultural codes that the writer and public have in common, whereas the private game involves the idiosyncratic and private deployment of linguistic possibilities, or the idiosyncratic deviance from the norm (Epstein Ch. 4).

More will be said about "play" and "game" as regards style, but we are moving towards an idea of individual style as being an idiosyncratic and characteristic method of using the elements belonging to a common system governed by rules and conventions (Epstein 24). That common system may belong to a particular period, genre or mode of discourse or a combination of them, but it is that language code or idea of rhetoric and how an individual writer uses language in terms of that language code that is significant, rather than the idea of an effective rendering of subject matter, although the influence on that rendering and our attitude towards that subject matter is also relevant. So, for our purposes, style resolves itself into two distinct kinds: individual style and conventional rhetoric. Anti-style, then, can also be of two kinds: that which breaks with the predispositions of the text itself, and that which goes against the common system of conventional rhetoric.

We can say that rhetorical conventions and forms are important in narrative texts and various effects can be created by conforming to them or not. These conventions depend largely on the mode of discourse adopted by the writer which generally has recognisable word and phrase types, ranging from the legal terminology of law books to the opening and closing formulae of fairy stories, as well as depending on the predispositions generated by the individual text itself (see Iser 4). The adherence to or deviation from conventions or individual predispositions in the text can be associated with the idea of play and game and all literary texts are, in a sense, playful, so that the degree to which they are playful or not creates certain expectations in the reader and is related to the question of style and anti-style.

In his essay "A Future for the Novel," Alain Robbe-Grillet points out that anti-rhetoric or anti-style is typical of the nouveau roman and, when it is a reaction against or a negation of common conventions or rules of rhetoric, is a sign of individuality. However, 
he emphasises that we are always the inheritors of a tradition, and innovation, and the nouveau roman can only exist in terms or what they are not (17). If innovation depends on the negation of rules or conventions, then the existence of these conventions is implied in spite of breaking with them, and we are just as aware of the rule as we are of its contravention. This means that we tend to judge new forms and styles in terms of the already consecrated conventions, and that anti-rhetoric or anti-style, and the fact that we consider it as such, suggests that the existence of such rules are constant in narrative in spite of the fact that part of the game of literature consists in breaking them. The effect of this kind of anti-style could be described as defamiliarisation, and postmodernist novels, which consciously break away from the norms of conventional narrative, emphasise the existence of these conventions, while they criticise assumptions that we may have about the relation between the language of fiction and the represented world, thus emphasising the nature of the narrative as text and artefact. As I say, the effect is one of defamiliarisation, which, in a sense, shocks the reader out of a passive complacency and highlights the artificiality of style or technique.

It has been suggested that anti-style involves the breaking of certain rules of rhetoric. However, Peter Hutchinson has written that "of all the games known to man, those in literature would seem to rely on rules least" (15). But since Sterne, there has been a tendency to flaunt the conventions of rhetoric and narrative so that, although there are conventions which are commonly adhered to, they can be played with for the sake of a particular effect. An ungrammatical statement in a text is striking and the consequence is to make us more aware of the rules or conventions themselves: breaking the rules brings about defamiliarisation.

At this point, perhaps a distinction ought to be made between "play" and "game," something which can be linked to our dual vision of style. The game has rules (rhetoric), but play can be considered as individual style which may contravene the rules of rhetoric. Hutchinson states: “A 'game' traditionally suggests 'rules' or 'conventions'; such concepts are indeed recognisable in certain literary games, but play does not imply such conventions" (14). The ideas of narrative as a game and the presence or absence of rules as regards style require the involvement of reader expectation, so that we should consider how the reader comes by these expectations and how they may be disappointed. Let us say that the rules of rhetoric can be considered as "laid down" but that there are techniques by which authors can manipulate their material in order to disappoint reader expectation, which is dependent on the existence of these techniques. Wolfgang Iser has written of "[the implied reader who embodies] all those predispositions necessary for a literary work to exercise its effect - predispositions laid down, not by an empirical outside reality, but by the text itself" (4). For the reader, then, games and play will stand out from the rest of the text as the game consists in going against the conventions of realistic writing already established in the text. So, at one level, anti-style involves this kind of play and can be considered simply as a sign of individuality.

These predispositions laid down by the text involve several elements dependent on a series of choices made by the author. They involve the selection of a particular mode of discourse, structure, narrator, perspective, chronology and so on; and the reader would normally expect the text to keep within the bounds of these predispositions that determine 
the narrative structure, as well as to follow the conventions of rhetoric associated with realistic writing in terms of the mode selected, whether it be non-literary (biography, epistle, history, journal) or belongs to a literary genre (gothic, detective, picaresque and so on). To go against these predispositions associated with these choices is a symptom of play, and a text that is all play or continually disappoints reader expectation would break with the norms of realistic discourses, bringing about defamiliarisation and its consequent effects. So, when we talk about anti-style, we are talking about style that, by playing with available possibilities, and going against the established predispositions, draws attention to the nature of style as such: the ultimate conclusion that we can draw from this is that the conventional is artificial, but, even more than that, the unconventional, rather than simply being a sign of arbitrariness or individuality, is equally so. Thus anti-style performs what Roman Jakobson calls the poetic function of language, although the effect brought about by deliberately breaking rules or deviating from the norm, is to draw attention to the nature of linguistic and narrative convention, which is not simply done for its own sake (350-77).

A related idea is that of "framing." We can say that the world itself as well as works of art (and here we do not just mean paintings) are organised and perceived through frames; that everything is framed and that these frames are what formally organise experience or narrative (Waugh 28). That is, frames are or involve the conventions that facilitate access to the text and imply the way of seeing or world view of the author. Style is a part of this process of framing as it is the manipulation of conventions as regards style which allows the existence of these recognisable patterns, which are necessary for communication. In fact, the conventions of narrative, including those regarding style, should not be considered as a constraint but, actually allow the possibility of narration. Moreover, we can say that the use of conventional practices and adherence to rules of rhetoric create the realistic fallacy, alluding to reality while they separate us from it. On the other hand, anti-style, or anti-rhetoric, highlights these facts, in particular drawing attention to the fact that our view of reality in narrative is governed by convention.

As regards this, Ortega y Gasset has pointed out that because of conventional framing (and by that I also include rhetoric), readers tend to "look right through [the pane and transparency that is the work of art] and revel in the human reality with which the work deals" (31). This means that by following conventions the reader focusses on the literary product and forgets about the process. Access to the text is facilitated and "reality" or a sense of reality is created by following conventional practices including those related to style. Hence, reality, or at least the realistic fallacy, is not opposed to convention but a product of it. Where we find anti-rhetoric or anti-style tends to be in playful texts which draw attention to the "frame," defamiliarising the rhetorical rules through which we are given access to reality and which we are accustomed to seeing through, thus drawing attention to the realistic fallacy and even the conventional nature of all forms of narrative.

Curiously, this defamiliarisation which lays bare literary and stylistic devices can be related to the use of parody in narrative. We could say that parody is a kind of anti-style (or can be considered as anti-style) in that it involves the laying bare of both similarity and difference: it invites the recognition of rhetorical rules, codes or conventions, and, while it makes use of them, also abuses them. Typically, in the novels which we consider as postmodernist, we find a contradictory phenomenon which both makes use of and subverts 
the conventions we recognise. However, Bakhtin sees this as true not only of postmodernism but of the novel as such. He writes that "[the novel] parodies other genres (precisely in their role as genres); it exposes the conventionality of their forms and their language" (5). So, while it incorporates certain conventions or rules, parody tends to involve ridiculous exaggeration, whereby these are distorted, defamiliarised and, therefore, challenged. Thus, the parody of a particular style, or of rhetorical rules is, essentially, antistyle. As parody thematises the artifice of narrative, language itself is also foregrounded as we are made aware of the nature of the conventions involved. Parodic narratives are always self-conscious in that they imply an awareness of the conventions of the mode adopted and, as this is done in an exaggerated manner, we also become aware of this and the limitations of that mode to represent reality.

Up to now, we have dealt with the question of anti-style in relation to a common system of rhetorical rules, but a few words of clarification are necessary. According to Crystal and Davy, in literature it is possible to introduce "any kind of linguistic convention without it being necessarily inappropriate and features from any other variety can be made use of in a literary context ... for a particular effect" (79). And they go on:

In a poem or a novel, one may find pieces of religious or legal English, or any other, which have to be understood in their own right before one can go on to assess their function in terms of the literary work as a whole. (79)

This suggests that, in the first place, the dimensions of situational constraint that apply to language in general apply to the modes of discourse which literature adopts - for example, questions of dialect or status require the writer to follow certain conventions as regards formality and informality, as well as requiring the use of certain word and phrase types (Crystal and Davy 64-77). The use of a particular mode or modes, then, generates a series of predispositions as regards the interrelationships of categories of discourse which can be defined as mutual dependence (as between legal and formal language), probable cooccurrence (conversation and informal language), possible co-occurrence (religious and informal discourse), and improbable co-occurrence (as between legal and informal language) (Crystal and Davy 89-91). When we find an example of improbable cooccurrence, we might call this anti-style, which involves incongruity or incompatibility in terms of the interrelationship of categories of discourse. This is not the time to set down the stylistic conventions for different modes of discourse or prose types, but we can say that the reader is intuitively aware of the appropriateness of a particular style, in the same way as he is aware of what is anti-rhetorical, incongruous, or incompatible. However, there is a broader context in which we can consider the rules of rhetoric.

If we go back to our idea of the frame, we recall that a series of predispositions are laid down by the text itself and, if we make use of narratology, we can suggest that these predispositions are related to a series of selections as regards time, mode and voice (these are broad categories of discourse suggested by Gerard Genette, 1980). More specifically, this requires, in conventional texts at least, stylistic uniformity as regards each of these categories of discourse. Any alterations to this stylistic uniformity, or transgressions within what is traditionally felt to be a single structure would be felt to be an infraction of the 
rules. These choices within categories of discourse, apart from the selection of a particular literary or non-literary mode, involve decisions as regards order, duration, and frequency (in time); distance and point of view (in mode); and the questions of tense, the existence of distinct narrative levels, and person (as regards voice). The choices made at the beginning of a narrative suggest the predispositions of the text and the tendency towards alterations and transgressions, of course, could be considered as anti-style. It has been suggested that this is a common occurrence in many postmodernist narratives and that it draws attention to the nature of the narrative itself, its style, and the conventions that have been both used and abused. Therefore, a text where we find continual alterations in perspective, person, frequency, or tense is a playful text which is unconventional and whose effect would be metafictional. It should be emphasised that these choices and alterations are, in the end, dependent on an awareness of conventional rhetoric, although the intention may be to question the validity of the conventions concerned.

There is, yet, an even simpler manner in which we can consider rhetorical conventions, and it is curious to note that, in these terms, as before, rhetoric is less a question of what to do than of what not to do. As we have suggested that parody as anti-style distorts or exaggerates aspects of a particular mode, then, we could say that it is an example of what not to do in most conventional narratives. As schoolchildren, many may remember classroom games which involved similar advice as regards what to avoid in speech or writing. An incomplete list of rhetorical "don'ts" would include hesitation, repetition, exaggeration, contradiction, evasion, omission, and there are probably many others. It is curious to note that, in much recent narrative, it is precisely this kind of anti-rhetoric that we find, as well as the kind of alterations we mentioned earlier. This kind of unconventional treatment in narrative draws attention to the nature of the style itself, but, above all, emphasises the idea of narrative as process rather than product, where all of the alternatives available to the author, his doubts and so on, are incorporated into the text. Thus, anti-style draws attention to the frame, the "pane and transparency," and places the reality represented in a secondary position. Another possible effect of altering the predispositions laid down in the text, or indulging in anti-rhetorical practices, is simply to bring out the playful element in the narrative. Curiously, much contemporary narrative does just this, and seems to play the game for its own sake, forsaking reality and foregrounding the fact that all the novelist has at his disposal is convention, or some kind of reaction to it.

Previously we mentioned that literary narratives make use of forms and styles which do not necessarily belong to the conventional literary repertoire (although having said that, the novel has always made use of non-literary forms of expression), like forms of speech, the language of commerce, law, architecture, and so on, as well as sub-literary forms like journalism, the detective story, comic books, dirty jokes, etc. As we tend to distinguish these forms from literary forms (tragedy or comedy), we might tentatively suggest that these non- or anti-literary modes are also anti-rhetorical, particularly bearing in mind what has been said about the incorporation of such forms as a symptom of the anti-traditional nature of the novel, which, more than any other literary form, has used forms which can be considered as such (Bakhtin 5). Moreover, many postmodernist narratives tend to mix 
and juxtapose these sub-literary forms to undermine our conventional expectations and draw attention to questions of authority, appropriateness and decorum.

One such example, to which we will return, is B. S. Johnson's Albert Angelo. The novel is about the protagonist, Albert, and tends towards a variety of modes of biography. However, different narrative modes and voices are juxtaposed in order to arrive at a complete description of him. This brings about an implicit, and sometimes explicit, struggle for authority among these different modes and voices with the underlying intention to show that no single version can be considered authoritative. A specific example is the use of children's essays which vie for authority with all the other narrative modes and voices, including that of their teacher, so that, even with the introduction of the "authorial" voice at the end, the result is to show that it is fallacious to consider the existence of an authoritative or official voice and, in turn, to undermine the "realism" of all the modes adopted.

We have said that all discourse types are dependent on certain conventions, and speech, or the presentation of speech, in narrative is no exception. If we consider that attributions to speakers and stage directions usually come at the beginning, end, or in a natural pause in the utterance of the speaker, anti-style involves placing them at any other point and would be, once more, unconventional, reminding the reader of the convention that has just been contravened. This, in fact, happens in some recent narratives whose reactions against these conventions for speech presentation can be considered as a symptom of a generalised reaction against conventions that still uphold the realistic fallacy.

Up to now, most of what has been said has dealt with reactions against the common systems of rhetorical rules and it has also been suggested that breaking the rules or the use of deviant style is a sign of idiosyncrasy or individual style. But what of anti-style at a personal level?

The text lays down its own predispositions and we have said that stylistic uniformity in a text is common and conventional. It is possible to suppose that we can arrive at the idea of some kind of a "norm" in an individual style of writing if we are able to appreciate some degree of constancy on the part of the writer. One such constant in a narrative text might be that of consistence as regards pace or speed, and the same might apply to point of view, person, tense, and so on, which, after all, are all stylistic choices. If we are able to become aware of such consistency in the text, then any kind of alteration might be considered as going against the established norms or style of the narrative, thus drawing attention to the nature of the conventions the author has adhered to previously. This is typical of many postmodernist texts, although it can be found in narrative virtually since its beginnings, and can be considered as essentially metafictional. Of course, if a text is full of alterations, then there is no established norm, and polymodality would thus be the distinguishing feature of that style. In such a text, there is a deviation from conventional narrative, bringing about a playful manipulation of reader expectation and with it, of course, defamiliarisation.

Due to what can be considered an ongoing dialogue with the novel form in the novels of B.S. Johnson and considering the author's desire to suggest the existence of alternatives to official or authoritative narratives, including his own, we find many examples of what 
we have been calling anti-style. His novels are full of features that might be considered as inappropriate or incongruous, and he often goes deliberately against established convention. The author himself wrote briefly about some of his work in Aren't you Rather Young to be Writing Your Memoirs (1973), and gave an indication of his thoughts regarding the question of style.

Talking about the novel we mentioned earlier, Albert Angelo, he speaks of himself as having discovered here his "own small voice," although this is probably meant ironically, and would refer only to the "Disintegration" section of the novel as he continually changes styles, person and modes; moving from dramatic presentation to third person narrative, to sections recounted wholly in the first, second or third person singular, first, second and third person plural, and so on. This, in itself, is anti-rhetorical, and might be considered a sign of idiosyncrasy, but what seems to have become the playful norm breaks down with his famous aposeopesis (interruption), which coincides with a sudden change in style, a change which we might suggest introduces that "own small voice" we mentioned: “ . . . he lived and loved to live in an area of absolute architectural rightness which inhibited his own originality and resulted in him being - OH, FUCK ALL THIS LYING" (163). The obvious shift from a formal third person narrative to the use of expletives in the first person could be considered as an example of anti-style and emphasises the artificial nature of the styles previously adopted. There is a clear mixing of modes and registers and the sudden introduction of a discordant note at this late stage in the novel seems highly inappropriate. However, it ironically suggests the inappropriateness and artificiality of the styles that precede it, even questioning the authority of the whole narrative.

There is a clear mixing of modes of discourse here, something which also happens in Christie Malry's Own Double-Entry, where the narrator explicitly draws attention to the fact in a self-conscious and metafictional manner: "That is enough of that [oratia recta] certainly. Let us subside into oratia obliqua" (65). Here the narrator draws attention to the limited nature of the use of a particular style, and breaks the rules somewhat by explicitly drawing the reader's attention to it, and the existence of an alternative. In the same novel, we find another relevant example of anti-style with the unconventional presentation of speech. One example is this: “'What I would like to,' said Headlam, 'do is to ..."” (102). This attributive phrase clearly interrupts the utterance rather than coming in a natural pause and suggests arbitrariness, where traditionally the novel seeks for a sense of the inevitable. As well as alluding to a number of alternatives to the chosen presentation of speech, a rhetorical convention has been clearly undermined, thus drawing attention to the conventional and fallacious nature of novelistic realism. In fact, Johnson undermines convention in a similar fashion throughout the novel by using parenthesis in the most unexpected of places.

In his last novel, See the Old Lady Decently, which is a perfect example of the kind of thing we are talking about, Johnson tends once more towards the continual alteration of styles, the creation of individual conventions, the use of intertextuality and the mixing of modes. Discontinuity, hesitations, and interruptions are all built into the text and what are identifiably realistic conventions are mixed with the clearly fictitious. The novel is full of parody and burlesque where he installs but at the same time subverts the rhetoric of a particular mode, mainly through the exaggeration of particular traits, ellipsis of significant 
features, or inappropriateness, thus contesting the reliability of the mode he uses. In particular, this kind of parody occurs with the styles of travel guides and history books.

The anti-stylistic nature of See the Old Lady depends, in the first place, on its fragmentary nature. There is no sense of uniformity here. There are continual shifts in point of view; changes in voice (from ulterior past to simultaneous present); changes of focalisation; the use of jokes and intertextuality; the use of collage and montage; interruptions; gaps/omissions; repetitions; hesitations, which are suggestive of pluralism and permutation; false starts; aposeopesis; a mixture of minimalism and exaggeration; a movement from a general historical view to a limited personal view. Specific authors, particularly Sterne, are parodied and we find throughout a tendency towards contradiction, incongruous juxtapositions, incomplete sentences, and so on. Johnson, in the manner of Sterne, also exaggerates authorial presence, continually drawing attention to and commenting on the act of narration.

This lack of consistency is clearly an example of anti-rhetoric. However, let us consider a specific text to illustrate this, one which parodies the conventions of the history textbook at a stylistic level, to show the limitations of this as a means of describing history or reality. We have already made it clear that all parody involves some element of antirhetoric and, in this case, the exaggeration of stylistic traits belonging to a particular mode, combined with the omission of important information like proper names and place names undermines the authority of this kind of rhetoric, precisely by drawing attention to the simple fact that it is rhetoric. Paradoxically, the dependence of a mode on certain stylistic features is emphasised here by the use of ellipsis:

They feasted in the Norman keep. He built the chapel and the third King's House in the wall.

His son rebuilt the chapel and his son had the idea of putting the roof on it. Their daughter-in-law raised the great terraces above the river and built the gallery called after. Her great grandson preferred to live in a little redbrick house outside the walls. His son was not so, but raised the height of the keep and built another tower. Our great contemporary then swept away the little houses that clung to the hillside, she gave them the push and they fell, fell. Another was drawn at the tails of horses, and hanged outside the gates. The old square tower was erected by the first or third one as a swimming bath.

The Maiden's Tower one of them went on to build as a special sign of favour for his Maids of Honour and it is now used as a laundromat. This one was formerly the seat of the Earl of, based within the boundaries of what is left of what used to be the outlaw's favourite haunt, the Forest of. (19)

Much of the text appears meaningless: personal pronouns lack antecedents, as do possessive pronouns. We lose any notion of place and a sense of generality is achieved when, ironically, textbooks are intended to be specific. Due to the juxtaposition of unfinished sentences, contradiction is also a feature of this text.

The text is essentially parodic. History textbooks depend a great deal on the use of proper nouns as they are about specific places and people, and Johnson intends that we become aware of the analogous relationship between this mode and realistic fiction. Thus he defamiliarises the conventions of the mode by omitting its most important feature 
(nominatives). Furthermore, the pronouns seldom refer to the nouns in the text, creating incongruities which allow us to speak of an example of a parodic anti-style whose effect is essentially metafictional. As we suggested, omission, contradiction, repetition of similar structures and incongruity all form part of anti-rhetoric.

Something similar happens when Johnson makes use of the mode of the tourist guidebook which he again parodies, and we also find ellipsis, contradiction and generality:

From Pass, a couple of miles to the east, half a dozen glaciers can be seen at once, and so near that their green fissures are clearly.

Light and shadow upon the cluster of peaks are magical in their changes at or, and the traveller who has looked up from the green to watch a snow-storm trailing its curtain across the crests, with perhaps a white summit standing serene above the cloud, will not readily.

Wooded but infertile are the most magnificent pastures. (34)

This text makes use of the most significant stylistic features of the tourist guide-book which Patricia Waugh has described as including generally an S-V-O construction or a passive impersonal one. This is suggestive of objective realism or reliability in itself and Waugh also highlights the "liberal use of colour adjectives" (73) and the specific nature of everything, ironically contradicted by the general tone caused by ellipsis, which is brought about by the "continual modification and qualification with much embedding of clauses" (73), which familiarises the reader with the landscape. However, this apparent objectivity is undermined by the heavy use of pathetic fallacy, typical of this mode: "summits standing serene" and a snow storm "trailing its curtain." These are, effectively, clichés which are readily assimilated by the reader and allow him to identify with and feel comfortable in a clearly humanised landscape (Waugh 73).

Once more, the ellipsis of place names leads to a generality which contrasts with the apparent specificity of the description (it is really formulaic, standard and non-specific) and leads to difficulty in arriving at any real understanding of a text which is totally lacking in context. Patricia Waugh states that these techniques "emphasise that this is not only a humanly but a verbally ordered 'natural' scene" (73). She goes on:

It is an essay in rhetorical and commercial persuasion rather than a "true" transcript [of a guide-book]. Yet the guidebook with its own aim of appealing to as many tastes as possible, merely exaggerates the methods of all prose discourse in making the specific carry the general implications of a particular ideology. Here this is laid bare as the height of generality is achieved by the complete omission of the substantial. (73-4)

The text is, therefore, anti-stylistic: syntax is disrupted and Johnson goes against not only the predispositions of the style adopted but also the more general rules of rhetoric through ellipsis and contradiction. Basically, he installs but at the same time contests the conventions he is using, a typical feature of many postmodernist texts, drawing attention to their nature, which is the nature of any objective mode of writing. The text becomes a metafictional critique of methods of realistic writing like history and guide-books but due 
to their inclusion within a novel, the criticism extends itself to the way in which all narratives tend towards distortion and fabrication.

Johnson strives in this novel to give a realistic account of his mother's life while at the same time reflecting the decadence of Britain and the Empire after the First World War. He is aware of the limitations of his narrative to achieve this, but by including different modes of discourse and shifting from personal reminiscences to general accounts from history books he draws attention to the nature of all of them and the result is defamiliarisation. He alludes to reality but falls short, as all of these modes do. His use of anti-style or anti-rhetoric here emphasises the nature of the conventions he is using at the same time as it foregrounds their limitations and the inevitable distortion and fabrication inherent in any narrative.

From all of this we can be sure of the existence of anti-style at both an individual and a more general level of rules of rhetoric. We have seen that parody is also a kind of antistyle as it embodies features that we have considered anti-rhetorical, and its overall effect, by its investigation of similarity and difference in terms of style, is to draw attention to the nature of the conventions that are used and abused.

In a sense, we can associate anti-style with the idea of framebreaking, as stylistic uniformity breaks down; or with the idea of short-circuit, as reader expectation is disappointed and the fictitious nature of what is narrated is foregrounded. All in all, antistyle can be said to stand out more than any adherence to rhetoric and is a postmodernist strategy which implies a metafictional commentary on the nature of language, style, narrative, and the conventions that govern them.

\section{Works Cited}

Bakhtin, M. M. The Dialogic Imagination: Four Essays. Trans. Caryl Emerson and Michael Holquist. Austin and London: U. Texas Press, 1981.

-----. "Epic and Novel." 1981. 5-28.

Brooke-Rose, Christine. A Rhetoric of the Unreal: Studies in Narrative Structure, especially of the Fantastic. Cambridge: Cambridge UP, 1981.

Chatman, Seymour. “The Semantics of Style.” Kristeva 1971 399-422.

Crystal, David and Derek Davy. Investigating English Style. London: Longman, 1969.

Epstein, E. L. Language and Style. London: Methuen, 1978.

Genette, Gérard. Narrative Discourse: An Essay in Method. Trans. Jane E. Lewin. Ithaca: Cornell UP, 1980.

Hutchinson, Peter. Games Authors Play. London and New York: Methuen, 1983.

Iser, Wolfgang. The Implied Reader. Patterns of Communication in Prose Fiction from Bunyan to Beckett. Baltimore: John Hopkins, 1974.

Jakobson, Roman. "Closing Statement: Linguistics and Poetics." Sebeok 1960 350-77

Johnson, B. S. Aren't You Rather Young to be Writing Your Memoirs. London: Hutchinson, 1973.

---. See the Old Lady Decently. Introd. Michael Bakewell. New York: Viking, 1975.

. Christie Malry's Own Double-Entry. Harmondsworth: Penguin, 1984.

Albert Angelo. New York: New Directions, 1987. 
Kristeva, J. et al., eds. Essays in Semiotics. The Hague: Mouton, 1971.

Ortega y Gasset, José. The Dehumanization of Art. Trans. Helene Weyl. Princeton: Princeton UP, 1948.

Robbe-Grillet, Alain. For a New Novel. Evanston, Illinois: Northwestem UP, 1989.

Sebeok, Thomas A., ed. Style in Language. New York: Wiley, 1960.

Waugh, Patricia. Metafiction. The Theory and Practice of Self-conscious Fiction. London and New York: Methuen, 1984. 